\title{
LEONIDAS YEROVI: PERSONAJE NOVELABLE Y HÉROE ROMÁNTICO
}

Resumen: Leonidas N. Yerovi (1881-1917) es uno de los escritores peruanos más importantes del Modernismo. Su amplia obra, aún poco estudiada, abarca artículos periodísticos, poesía, crónica y teatro. En el presente artículo, se estudia una de las líneas de investigación que ha seguido la crítica literaria al momento de investigar a Leonidas Yerovi como autor: las características literarias de su vida. Con miras a ese objetivo, se revisan aspectos importantes desde los cuales se ha interpretado

* Paulo Piaggi Arellano es bachiller en Literatura por la Universidad Nacional Federico Villarreal y, actualmente, trabaja en su tesis para la Maestría en Literatura Hispanoamericana en la PUCP acerca del teatro de Leonidas N. Yerovi. Se ha desempeñado como tutor de lenguaje en la UPC y trabaja como jefe de prácticas en los cursos de Teatro y Poesía de Estudios Generales Letras en la PUCP. Ha participado en distintos congresos sobre literatura y publicado reseńas y artículos en revistas a nivel nacional. En 2015, obtuvo el primer puesto en el Concurso de Ensayo Corea organizado por el CEO (Centro de Estudios Orientales) y la embajada de Corea del Sur en Lima con un trabajo acerca de la novela La casona de los patios de Won-Il Kim. 
su biografía: su muerte trágica, la bohemia y la amargura detrás de su risa. Se demuestra, de esta forma, los procesos por los cuales se ha buscado ficcionalizar a este personaje histórico y convertirlo literariamente en un héroe romántico, como manera de ejercer la crítica y la creación literarias.

Palabras clave: Leonidas Yerovi, literatura peruana, modernismo, crítica literaria.

\section{LEONIDAS YEROVI NOVELIZABLE CHARACTER AND ROMANTIC} HERO

Abstract: Leonidas N. Yerovi (1881-1917) is one of the most important Peruvian writers of the Modernismo. His extensive work, not yet properly studied, covers articles, poetry, chronicles and theatre. In the present article, we study one of the lines of inquiry followed by the literary criticism when researching Leonidas Yerovi as an author: the literary characteristics of his life. With that objective in mind, we review important aspects around which his biography has been interpreted: his tragic death, the bohemianism and the bitterness behind his laughter. We demonstrate, thus, the processes by which the critics have sought to fictionalize this historical character and turn him into a romantic hero, as a way of practicing literary creation and criticism.

Keywords: Leonidas Yerovi, Peruvian Literature, Modernismo, Literary Criticism.

\section{Introducción}

$\mathrm{L}$ uis Alberto Sánchez, en su libro titulado América: novela sin novelistas (1933), propone la idea de que nuestro continente, aquella Nuestra América de Martí, es un personaje romántico, materia fértil para la escritura de novelas. "Desmesurado y lírico, pintoresco y bullicioso, [el continente americano] presenta las características de un personaje del 50" (Sánchez, 1933, p. 9). No obstante, nuestros escritores han preferido la subjetividad de la lírica a la objetivación de la novela. América sería, en esos tiempos, para Sánchez (1933), una "tierra novelesca, pero no tierra novelista" (p. 13). En este caso, el romanticismo es entendido como una actitud o una "aptitud espiritual" (Sánchez, 1933, p. 11) y no como solo un movimiento artístico e intelectual con fechas delimitadas.

La idea que subyace a este postulado de Sánchez es que existen, en la realidad, cualidades artísticamente reconocibles. América sería depositaria de romanticismo desde su nacimiento. De allí que apele a esta cualidad incluso dentro de la escritura del Inca Garcilaso de la Vega (Sánchez, 1933, p. 11). Además, esta realidad no es silenciosa, sino que 


\section{LEONIDAS YEROVI: PERSONAJE NOVELABLE Y HÉROE ROMÁNTICO}

reclama ella misma su transvase a la literatura: América no solo carecería de novelistas, sino que, por su propia naturaleza, exigiría ser novelada.

Estas dos ideas, que existen realidades con cualidades literarias reconocibles y que estas realidades exigen su escritura, son reformuladas por el crítico Luis Fabio Xammar en el primer capítulo de su libro Valores humanos en la obra de Leonidas Yerovi (1938). Si bien Xammar no cita o nombra a Sánchez, son notables ciertos indicios de diálogo con el libro de este mencionado. En primer lugar, ambos textos comienzan con capítulos cuyos títulos son sintácticamente similares: "América: personaje romántico", en el caso de Sánchez, y "Yerovi: personaje novelable", en el de Xammar. Asimismo, pueden hallarse segmentos en Xammar que funcionan como una reformulación o una respuesta a las interrogantes de Sánchez. Afirma así que "hoy ya se puede tener ciega confianza en un futuro novelado del Perú, hecho de su propia riqueza inmanente y vital” (Xammar, 1938, p. 12), como clara respuesta a la interrogante sobre la carencia de novelas que había notado Sánchez apenas unos años antes.

El caso de Leonidas Yerovi es emblemático, ya que esta preocupación por la novelización de su vida que surge con Xammar puede notarse en la manera en cómo se ha tratado su biografía posteriormente, y ha derivado en la publicación de La casa de tantos (2001), novela de Nicolás Yerovi basada en la vida de su abuelo. En el presente artículo, revisaremos aquello que la crítica ha formulado acerca de las cualidades literarias de la vida de Yerovi teniendo en cuenta que el inicio más claro de esta noción se encuentra plasmado en medio de una tensión entre el interés por Yerovi como personaje (y su construcción como héroe romántico) y la preocupación por el futuro de la novela en Hispanoamérica.

\section{La muerte de Yerovi}

$\mathrm{E}$ n la tesis doctoral de Willy Pinto Gamboa, La sátira en Valdelomar y Yerovi (1973), se incluye un capítulo acerca de la biografía de Leonidas Yerovi. Al comienzo de este, escribe Pinto: "Generalmente, cuando se trata de la obra literaria de Leonidas Yerovi, se prescinde del aspecto biográfico como si la muerte violenta que tuvo el poeta hubiese pospuesto todo interés por su vida anterior" (1973, p. 109). Esta afirmación nos parece precisa, desde el momento en que la mayoría de estudios no solo mencionan las circunstancias de su muerte y la hacen un punto central, sino que, normalmente, se incluye como paratexto ${ }^{1}$ el discurso

1 Un paratexto es aquel elemento que acompaña al texto pero que no es parte necesaria de él. Pueden ser los títulos, prefacios, epílogos, etc. (Genette, 1989, p. 11), pero también otro tipo de escritos relacionados históricamente con la obra o el escritor. 
pronunciado por Abraham Valdelomar ante la tumba de Yerovi (Yerovi, 2006; Rivera Saavedra, 2007; Chávez Costa, 1991; Tamayo Vargas, 1969). Por lo tanto, si queremos explorar los motivos de la importancia otorgada a la trágica muerte de Leonidas Yerovi por la crítica, dentro del marco de las cualidades literarias que su vida presenta, este texto inicial de Valdelomar puede ser un buen punto de partida.

El Discurso en el entierro de Leonidas Yerovi de Abraham Valdelomar fue publicado en el diario La Prensa el 17 de febrero de 1917, apenas dos días después de la muerte del poeta el 15 de ese mismo mes. Comienza de la siguiente manera:

\section{Señores:}

Un hombre malo vino desde muy lejos, desde unas cosas rocallosas, desde un mar siempre colérico bajo el cielo gris. Después de llegar entró en nuestra casa y allá, abajo, se lo llevó para matarlo. Mis compañeros salieron a buscarlo, y cuando lo vieron ya caído y lleno de sangre, se pusieron a llorar.

Oye, hermano Leonidas, yo te quiero contar lo que ha pasado. Yo vivo allá, en el Barranco, junto al mar. Yo estaba sońando, a la aurora, cuando entró mi madre sollozante, y me dijo: “¡Corre, corre! ¡Un hombre malo ha matado a tu amigo! ¡Corre!”. (2006, p. 599)

Este discurso, como es posible observar, utiliza un lenguaje simplísimo y explica los hechos sin entrar al trasfondo pasional del asesinato de Yerovi. El texto menciona al asesino como un "hombre malo" sin reconocer ninguna interioridad psicológica ni motivación externa a sus acciones, más allá del hecho de ser "malo", venir de una tierra hostil (Chile) y haber sacado a Yerovi de aquella casa que comparte con Valdelomar (el diario La Prensa). La incomprensión del hecho se acentúa en todo el discurso con el objetivo de lograr una profundidad emocional sacrificando cualquier análisis racional de los hechos. Después del primer párrafo, en el cual se dirige conscientemente a un auditorio, el narrador cambia a la segunda persona para dialogar directamente con el difunto, a quien llama "hermano". Esta cercanía, reforzada por el lenguaje sencillo en que está escrito el texto, funciona como un mecanismo que abre el mundo interno del narrador utilizando un estilo confesional.

A continuación, se nos describe una escena inverosímil cuya finalidad es mostrar el estado de aturdimiento casi onírico en que se encuentra el narrador en el velorio hecho en el diario La Prensa: 


\section{LEONIDAS YEROVI: PERSONAJE NOVELABLE Y HÉROE ROMÁNTICO}

Luego entraron a la sala tres hombres con unas túnicas blancas y unos guantes transparentes y se dirigieron a ti, con unos como cuchillos. $\mathrm{Y}$ yo entonces me acerqué, porque creí que iban a hacerte daño.

Descubrieron tu cuerpo, desnudo, blanco y rígido. ¡Desnudo, blanco y rígido! ¡Desnudo, blanco y rígido sobre la mesa dura! Yo comprendía, hermano, que tenías frío, que te morías de frío y no podías hablar. Y quería cubrirte, pero yo no tenía con que cubrirte. Abajo, la máquina empezó a vibrar: rum-rum, rum-rum, rum-rum; y empezó a temblar la casa y yo tuve miedo. Entonces, con sus hojas de acero, frías, destaparon tu pecho como se destapa un ataúd. Y yo empecé a temblar, a temblar, Leonidas, a temblar por ti que no te quejabas; a temblar por tu carne joven que el cuchillo surcaba tan hondo, pero no manaba sangre de tu cuerpo. Yo decía: ¿Cómo es posible que lo estén matando y que no sangren sus heridas? ¿Cómo es posible que lo estén matando y que nadie lo defienda? Me abalancé, pero me detuvieron. Yo no podía llorar, pero todos lloraban, lloraban, como si alguien se hubiese muerto. (Valdelomar, 2006, p. 600)

Las repeticiones constantes ("Desnudo, blanco y rígido", "Y yo empecé a temblar, a temblar, Leonidas, a temblar por ti...") parecen balbuceos de incredulidad ante lo espantoso de la escena. Todo el discurso es una exposición de estupor ante la muerte de Yerovi, que se manifiesta como la incapacidad física de llorar. La comprensión y el llanto llegan unidos al final: "Entonces se fueron todos. Se hizo de noche. Yo, mirándote, mirándote, comprendí que tú ya no estabas allí. Y me puse a llorar" (Valdelomar, 2006, p. 601). Este discurso se presenta como una narración que muestra la subjetividad de Valdelomar y como lamento por la muerte de su amigo, con elementos fantasiosos (como el corazón extirpado al cuerpo todavía latiendo en la mano de uno de estos personajes misteriosos que realizan esta autopsia macabra) que resaltan el aturdimiento ante el horror y concluye con la aceptación de esta tragedia a través del llanto.

El motivo por el cual este discurso aparece constantemente en la bibliografía sobre Yerovi no parece ser por la información que pueda proporcionar acerca de las circunstancias de su muerte, sino que el texto mismo y su autor son razones suficientes para incluirlo. Que Abraham Valdelomar haya publicado un artículo que, en toda regla, podría ser considerado 
como un cuento modernista acerca de la muerte de Leonidas Yerovi es más que prueba suficiente de las cualidades literarias de esta. Opina Tamayo Vargas (1969) que Abraham Valdelomar "pronunció unas extrañas y sugestivas frases en las que, al lado de la emoción vivamente expresada, se apreciaba una nueva línea estética” (p. 11). Además, la familiaridad del trato que emplea Valdelomar es una muestra de la pertenencia de Yerovi a la bohemia de su tiempo ${ }^{2}$, lo que incrementa su interés como personaje histórico. Luis Fabio Xammar pinta a nuestro autor como criollo bohemio, engreído, dilapidador, aventurero e inteligente que murió en su ley:

Lejos de sorprender la muerte a Yerovi, él es el que sorprende a la muerte, recibiéndola tal como siempre lo hubiera querido, entre un poema frustrado y unas fiestas próximas de Carnaval; entre la mesa de la redacción y la calle limeña por antonomasia, el jirón de la Unión, como una exaltada médula espinal de la ciudad. (1938, p. 11)

Esta manera de morir es propia de un héroe romántico, por su enfrentamiento con el destino, y será retomada en la novela de Nicolás Yerovi más de seis décadas después. Xammar parece presentarnos a Yerovi como una parte integral de Lima y su muerte como la culminación perfecta de su vida para convertirla en una historia que, nos dice, quizá le hubiera tocado a él escribir (Xammar, 1938, p. 13).

Uno de los dos textos importantes que narran la muerte de Leonidas N. Yerovi es el de Augusto Chávez Costa y aparece en su libro Periodismo y humor (1991). En sus primeros capítulos, el autor nos presenta con lo que podría leerse como una crónica policial del asesinato de Yerovi en 1917, seguida de información sobre su traslado al hospital, los motivos del crimen y el juicio consecuente. El poeta fue asesinado a las afueras del diario La Prensa, cuando, en medio de una pelea cuerpo a cuerpo, el chileno José Manuel Sánchez sacó su revólver y le disparó cuatro veces. El motivo fueron los celos que este sentía al creer a Yerovi su rival por el amor de la actriz argentina Ángela Arguelles, con quien ambos habían tenido relaciones en algún momento y Sánchez siguió desde Buenos Aires para cortejarla.

2 El tercer tomo de sus obras completas que venimos citando incluye, además, otros textos sobre la muerte de Leonidas Yerovi de personalidades importantes de la época como Mariátegui, Edwin Elmore, Federico More, Óscar Miró Quesada y Enrique A. Carrillo. 
Augusto Chávez Costa añade muchos detalles interesantes sobre el caso, como, por ejemplo, las personalidades que cargaron el ataúd de Leonidas Yerovi al salir de La Prensa: Hermilio Valdizán, Oswaldo Aguirre, Alberto Ulloa Sotomayor, Estenio Meza, Abraham Valdelomar y José Graña (Chávez Costa, 1991, p. 25). Estos datos resaltan la importancia de Yerovi como hombre de su tiempo y personaje histórico. El segundo capítulo de Periodismo y humor (1991) concluye la narración del entierro haciendo un paralelo entre nuestro poeta y José Santos Chocano:

Leonidas Yerovi murió a los 35 años de edad. Había nacido el veintiocho según unos, y el nueve de setiembre según otros, de mil ochocientos ochentiuno. Como José Santos Chocano, poeta de su misma generación, dato destacable y significativo, ambos limeńos y con obra abrumadoramente popular, que alcanzaron, igualmente, en vida, la consagración en el Perú y en el extranjero, estuvieron marcados por el mismo signo trágico a la hora de la muerte. Ambos, con la diferencia de quince años, fueron ultimados alevosamente por dos ciudadanos chilenos, y por fútiles motivos. Los dos hechos luctuosos son tan injustos que carecen de justificación, por lo que resultan tan malvados como repudiables. (Chávez Costa, 1991, p. 26)

Quizá este paralelo resulte más relevante por el olvido posterior que estos poetas han sufrido por parte de la crítica que por las coincidencias de sus muertes. Tanto El cantor de América como El joven X (seudónimo de Yerovi) se encuentran hoy en los márgenes de nuestro canon literario, aunque probablemente por motivos muy disímiles.

En 1938, el libro de Xammar había reclamado la escritura de una novela sobre la vida de Leonidas Yerovi y la respuesta, como ya se ha mencionado, llega en 2001, con la publicación de La casa de tantos de Nicolás Yerovi, nieto del poeta. Si en algo esta obra sigue la línea propuesta por el crítico es en comenzar con la narración de su muerte y presentarnos un personaje desafiante ante ella. Se nos muestra a un Leonidas Yerovi que se ríe de sus heridas, y es capaz de ver la ironía y el absurdo de su situación. 
Recordó sin habérselo propuesto que tres años atrás, desde Buenos Aires, había escrito para La Prensa una crónica elogiando los servicios de la Asistencia Pública en esa ciudad, y las palabras le regresaron a la mente como si alguna vez hubiese pretendido aprenderlas de memoria:

"Aquí no se coge a un herido de los sobacos y de las corvas entre dos compasivos transeúntes que le hacen recorrer la ciudad de botica en botica hasta hallar aquella en la que no se nieguen a proporcionarle los primeros auxilios. Aquí os acercáis a un teléfono, participáis el suceso a la Asistencia y uno de los automóviles de ésta acude en poquísimos minutos y si la herida no es mortal de necesidad, en noventa casos de cien, contribuye a salvar a la víctima con su presteza”. (2001, p. 13)

El Yerovi de la novela percibe la ironía de su muerte como percibió la de su vida y se enfrenta a ella con su hábito risueño. Cuando intentan desvestirlo para examinarlo, se queja de que sus desnudeses son solo de su señora (Yerovi, 2001, p. 14) y cuando el doctor no quiere que nadie entre, este replica que dejen pasar a Luis Fernán Cisneros, porque le debe plata (Yerovi, 2001, p. 26). Esta forma de representación, más que intentar mostrarnos ciertos delirios del poeta antes de morir, responde a la necesidad de convertirlo en un personaje romántico, de otorgar a su humor un significado más profundo como un enfrentamiento a la tragedia de la vida. Según Rafael Argullol:

La ética subjetivista del héroe romántico se alimenta — no formal y melodramáticamente, sino "en propia carne" - de lo que podríamos calificar de "fondo heroico del arte": un conjunto de normas implícitas de conducta moral que reemergen acompañando a toda poesía y a todo pensamiento integralmente trágicos que mueven a la aceptación noble y desnuda del principio de competición que enfrenta a hombre y Destino. (1999, p. 270)

La risa de Yerovi se nos presenta como la aceptación risueña de su destino trágico, de ese "sorprender a la muerte" propio de un personaje romántico. Esta es una característica

3 El nombre de esta crónica es "A mal tiempo, buena Asistencia. Un record. De la cama al solio. Americanismo" y fue publicada en La Prensa el 6 de junio de 1914. (Yerovi, 2006, p. 527). 
que ha seguido también la crítica en varios ámbitos, como desarrollaremos más adelante. La respuesta de Yerovi ante la muerte se nos muestra como la misma que ante la vida y se construye, por lo tanto, como un personaje coherente en su actitud contestataria, ya que busca vivir y morir bajo sus propios términos, tal como plantea Xammar que lo hizo, y como un héroe romántico que reconoce noblemente su destino trágico (e irónico).

\section{La vida del criollo y del bohemio}

ntre las fuentes que tenemos sobre la vida de Leonidas N. Yerovi, se encuentran algunas
publicaciones de la época y testimonios de sus familiares que han sido recogidos por Augusto Chávez Costa (1991). Sin embargo, la crítica, en muchas ocasiones, ha preferido transmitir una imagen integral del poeta, alejada de datos históricos y fundamentada en ciertos poemas que han sido considerados representativos. Uno de ellos ha sido el titulado "Servidorito" (1908), el cual Yerovi subtitula "autobiografía” y que es citado solo parcialmente, debido a su extensión, y escasamente comentado.

Pues señor... hace veinte años

y seis más, cifra cabal,

nací en esta capital

y me envolvieron en paños

y usé mi primer pañal

mi partera -ipobre!- que era

un fósil para un museo

y hasta miope aunque partera,

al verme sano a su vera

dicen que dijo: ¡Qué feo!

Y por miopía o rencor

añadió hablando al doctor:

-¡Y no es hombre! ¡Mujer es!

(lo que quince años después

desmintió su hija menor).

(...)

Y sin sentir afición 
por ninguna profesión

y tras ensayos diversos

me dediqué a medir versos

con la peor intención.

¡He hecho más!... "A una suegra”

"A un calcetín", "A un beodo",

"Al mar", "Al espacio", "Al lodo",

(...)

¿Mis aficiones?... Teatrales.

¿Mis gustos?... Los naturales.

Las corrientes mis desgracias

y mis vicios los usuales

y mi salud... buena, gracias.

Y como hasta hoy no he sufrido

nada en mi bien o en mi mal

que valga el ser referido,

doy esto por concluido

y pongo punto final. (2006, pp. 416-417)

Willy Pinto Gamboa cita estas secciones del poema (Pinto, 1973, pp. 109-110) y relaciona el final con el "Arte Poética" de los Cantos de Vida y Esperanza de Rubén Darío (Pinto, 1973, p. 110). Mateo Chiarella Viale también cita grandes extensiones de este texto, pero sin más comentario que mencionar cómo Leonidas Yerovi "bromea sobre su nacimiento y juventud" (2012, p. 35). Esta utilización del poema parece servir solo como una muestra cabal de la relación entre la vida y la obra del poeta, pero no pretende analizarse más allá de esa idea. Como diría Luis Alberto Sánchez, "a Yerovi se le ha analizado, hasta hoy, superficialmente" (1966, p. 1206). Sin embargo, habría que preguntarse si aquella superficialidad se encuentra en la crítica o es parte de su obra misma. En "Servidorito", se construye un yo lírico picaresco, quien es capaz de burlarse de sí mismo y, por lo tanto, ocupa un lugar privilegiado para reírse de la sociedad. Todos los mecanismos empleados fortalecen este efecto de liviandad como actitud ante la vida, pero, por esta misma levedad, no parece merecer un análisis profundo, que vaya más allá de la nota biográfica. 


\title{
LEONIDAS YEROVI: PERSONAJE NOVELABLE Y HÉROE ROMÁNTICO
}

Otro poema que es citado en parte es "Pasión tendera" (1903), que, según Chávez Costa, hace referencia a su "primer eventual y fugaz empleo" (1991, p. 33) como dependiente de una tienda. Le dice, en este poema, a una de sus clientas:

\author{
¿Por qué si mi amor notáis \\ -pues él hace que me venda- \\ ya no venís a mi tienda \\ y todo en otra compráis? (Yerovi, 2006, p. 303)
}

La suerte que ha tenido este poema es curiosa, ya que, si se lee hasta el final, el que escribe esos versos parece ser el dueño de la tienda, quien, al enterarse de la deuda de la señora, prefiere mandar a cobrarle los treinta soles que a entregarle la carta de amor. Esta asociación entre el poeta, su primer empleo y la escritura del poema parece iniciarse con Chávez Costa (1991), pero es retomada en la novela de Nicolás Yerovi, en donde se narra toda una aventura amorosa a partir de esos versos, que concluye con el poeta siendo perseguido por un militar, marido de la mujer, semidesnudo:

Bastó que el poeta lo viera bajo el umbral de la puerta de ingreso del gran almacén, buscándolo con la mirada encendida por la furia, para que apoyándose sobre el tablero del mostrador lo salvara de un salto y se largara a correr como una exhalación hacia la calle de Espaderos y el militar lo siguiera bufando y lanzando improperios y maldiciones, llevándose de paso a una señora gorda que largaba alaridos desquiciantes y descalabrando a un gendarme raquítico que intentó sin éxito detener la persecución haciendo sonar un pito. (2001, p. 129)

En ambos casos, el interés por el poema surge por su relación con la biografía del poeta, en un caso, real, y, en el otro, novelada. Debido a ello, ambos prescinden de los versos finales, de lo que podríamos llamar el remate del poema. Esta reticencia a tratar con esos versos burlescos y quedarse con la anécdota puede responder a una visión negativa de la crítica a lo cómico, a lo burdo que puede resultar explicar el chiste. Para evitar eso, José 
María Salcedo, en su prólogo al segundo tomo de las obras completas de Leonidas Yerovi, escribe sobre los versos citados:

¿Qué reclama Yerovi? ¿El desamor de la dama o su preferencia por la competencia? ¿Qué le exigía? ¿Su aprecio o su plata? ¿O las dos cosas a la vez? ¿Su aprecio era su precio? ¿El precio de Yerovi? Sus llantos a raudales en las telas de la tienda. Y ella compra en otra. El error del vendedor fue demostrarle su amor. No se sabe si la dama regresó y triunfó el vendedor, ni si Yerovi vendió ese verso y triunfó el escritor. Pero ese verso se convierte en toda una metáfora premonitoria del quehacer de Yerovi porque su obra, o gran parte de ella, fue una constante recreación irónica de lo que la realidad le imponía. (2006, pp. XIX-XX)

Si se tomase un poema de cualquier otro autor, se sacasen algunos de sus versos, olvidando la integridad del poema como obra, se los asociase a la biografía del poeta y se los convirtiese en una metáfora de su creación como una "recreación irónica de la realidad", seguramente otros críticos habrían respondido oportunamente que es necesario contextualizar los versos y no caer en una falacia biografista. No obstante, cuando se trata de la poesía de Leonidas N. Yerovi, lo que parece importar no son los poemas, sino aquellos retazos, aquellos versos sueltos que pueden utilizarse para lograr una imagen del poeta como un bohemio, como un criollo burlón y romántico.

Con esto, no afirmo que lo planteado por Salcedo sea falso. Efectivamente, gran parte de la obra de Yerovi puede ser considerada una recreación irónica de la realidad. Lo que busco mostrar es la línea que han seguido ciertos autores en la utilización de estos versos aislados del poema. En esta práctica crítica puede observarse un interés claro por Leonidas Yerovi como personaje en desmedro del interés por sus poemas como unidades semióticas cerradas, como obras literarias merecedoras de una lectura por su valor intrínseco. Esto les posibilita tomar un poema satírico, en el cual triunfa el lucro de un comerciante sobre su enamoramiento, y hacer que el poeta asuma sus versos como expresión de su experiencia vital e incluso su conciencia creadora.

Según Ricardo Silva-Santisteban (1993), "existe en todas las concepciones de los poetas románticos una identificación inseparable entre el poema y su ejecutor” (p. 33). En 
ese sentido, al buscar convertir a Yerovi en un personaje romántico, lo han vuelto también un poeta romántico, por aquella conexión entre la obra y la subjetividad de su creador. De acuerdo a Argullol (1999), "la identificación heroica entre el artista y sus personajes es el gran vínculo que da pie a la seductora veracidad, más allá del recurso a fantasías y a leyendas, de los argumentos románticos” (p. 29). El que Xammar diga que quizá hubiese correspondido a Leonidas Yerovi escribir la novela de su vida es perfectamente congruente con esta identificación entre poeta y obra. En definitiva, Yerovi, para ser un personaje/héroe romántico debe volverse primero un poeta romántico en todos los sentidos de la palabra, y muy a pesar de su exterior de humorista y satírico.

Quizá el mejor intento de construir una visión integral de Leonidas Yerovi como personaje sea la de Luis Fabio Xammar, quien lo comprende a partir de tres términos: inadaptación, desadaptación y bohemia. El Yerovi de Xammar "vive una vida sin método, sin cauce, intensa, torrentosa y aplacada" (1938, p. 14). En una tensión entre el dinamismo y la pereza, es un eterno inconforme que, con sus bromas inofensivas, muestra a la sociedad sus aspectos risibles y absurdos. Dentro de "la encendida y álgida bohemia que significó una generación periodística brillante, sin antecedente" (1938, p. 14), el poeta se esforzó por "adoptar un gesto cívico" (1938, p. 14), que su propia vida desordenada no le permitió concluir en su "obra en promesa". Vida sin método, capacidad crítica por su inadaptación, "gesto precipitado de turista angustiado" (1938, pp. 14-15), estos son los impulsos emocionales que dirigieron o descarrilaron a Leonidas Yerovi, y desembocaron en su bohemia, más humana que literaria (Xammar, 1938, p. 17). Xammar ilustra esta visión con unos versos del poema "Consejos interesados":

Mas si cariño tu pecho ansía

y necesitas, Aurora mía,

quien te idolatre con frenesí,

quien te dedique su pensamiento,

quien no te olvide por un momento...

vuelve los ojos, cese tu llanto,

¡fíjate en mí!... (Yerovi, 2006, p. 477) 
Según Xammar (1938), este poema muestra "la jactancia inofensiva y simpática que siempre puso a su ventura de amor" (p. 15). Como puede observarse, la visión que nos propone el crítico de Leonidas Yerovi es la de un personaje romántico, a la deriva, guiado por sus impulsos emocionales. Amor, amargura, risa, son algunas de las emociones que lo llevan a ser un inconforme, y a convertirse en escritor y bohemio.

\section{La amargura de Yerovi}

— n su famoso poema "Reír llorando", el poeta mexicano Juan de Dios Peza (1852-1910) Emenciona al personaje Garrik, un actor de Inglaterra capaz de cambiar el spleen de los altos lores en carcajadas, pero incapaz él mismo de reír. Siguiendo este mismo tópico, la crítica de Leonidas Yerovi siempre ha tenido la necesidad de enfatizar la amargura que se esconde detrás de sus risas. Federico More (1989) identifica en la poesía de Yerovi una "ternura un poco amarga" (p. 97), Luis Fabio Xammar (1938) opina que, al referirnos a Yerovi, "hay que hablar más que de su tristeza, de la enorme amargura que sobrecoge el destino de su obra” (p. 55) y Mateo Chiarella Viale (2012) titula un capítulo sobre la biografía de Yerovi "El alegre melancólico" (p. 35). Tal como Luis Alberto Sánchez veía a América como un personaje romántico, los críticos parecen haber buscado convertir a Yerovi en uno. Su risa risueña solo cobra sentido como un modo de enfrentar la tragedia de la vida, el sufrimiento del poeta es una cualidad estética necesaria para convertirlo en un ser literario.

Un poema que analiza Luis Fabio Xammar es "Versos de carnaval", subtitulado "(Pierrot estaba y no estaba, pero yo estaba...)". En este texto, el yo lírico se encuentra con Pierrot ${ }^{4}$ en el pavimento y lo conmina a levantarse. Juntos, se dirigen a un local en donde encuentran a Colombina con un amante.

¿Estaba muerto? ¿Soñaba

con ella? ¿Estaba dormido?

No lo sé, ni me importaba

Pierrot estaba y no estaba

Pero yo estaba bebido... (Yerovi, 2006, p. 593)

4 Pierrot es un personaje de la comedia del arte muy popular en los carnavales de principios del siglo XX en América Latina. Su imagen es la de un payaso triste, cuyos colores son el blanco y el negro, y llora por su amada Colombina. 
Según Xammar (1938), este poema es un "drama tan completamente dramático, que al mismo tiempo es esencialmente absurdo" (p. 21). Yerovi "resuelve la realidad por el absurdo" (1938, p. 21), pero este absurdo es, al mismo tiempo, la solución lógica, el tener consciencia de su estado mental alterado. El crítico se esfuerza por encontrar en estos versos una profundidad plenamente humana y dramática a través de un Pierrot que considera "pura ficción” (1938, p. 21). Yerovi crearía un "anti-pierrot digno, que pueda erguirse ante esa prostitución genérica a que lo han sometido los literatos” (1938, p. 21). La imagen del Pierrot lloroso no le place a nuestro poeta, como hombre de aventuras bohemias que enfrenta la realidad a través de la burla. Xammar, en definitiva, interpreta este poema como una muestra de la autenticidad sentimental y dramática de la poesía yeroviana.

Pero es el drama que no concluye, que vive en su muerte en un paraíso absurdo, inconfundible e inconfundido, donde acude el poeta como a un hogar dolorido y risueño, pero donde nuevamente se ve en la dura ley de añorar la tibieza que no logra completamente. La fugaz temperatura de un sueño inconcluso, afanoso y libre, que insinúa su ala acogedora, para inmediatamente interrumpirse en realidad. Brusca caída entre dos mundos astrales dibujados con humo y carne, ambos perecederos, precisos e incitantes, porque alientan una áspera esperanza, y que al mismo tiempo bosquejan el ancho gesto de la muerte. (1938, pp. 23-24)

Esta es la conclusión del crítico después de los últimos versos del poema:

Y mientras yo desvaído, de mi suerte blasfemaba bajo el rencor del bandido ¿Pierrot estaba? ¡No estaba! ¡Pero yo estaba molido! (Yerovi, 2006, p. 595)

Xammar parece obviar deliberadamente la anécdota jocosa presente en la composición, que estaba basada en la repetición de la presencia y la ausencia de Pierrot ("Pierrot estaba y no estaba"). El título del poema, "Versos de carnaval", nos da una pista 
acerca de la identidad desconocida de este hombre disfrazado de Pierrot, cosa que era muy común en los carnavales a principios de siglo XX. Aquella Colombina, a su vez, era UNA Colombina de tantas mujeres que utilizaban ese disfraz, $y$, coincidentemente, resulta ser la amante de ese Pierrot particular. En la pelea, el poeta sale a defender a su acompañante, y el penúltimo verso, que modifica mínimamente la sintaxis y los signos de puntuación, se decide por su ausencia: Pierrot lo abandonó cobardemente. La resemantización de aquel estar y no estar, que muestra la naturaleza del disfraz vista desde una conciencia perturbada por el alcohol, es el remate humorístico de la anécdota bohemia. ¿Cuáles son esos mundos astrales que caen para Xammar? ¿Cuál aquel "gesto de muerte”? El poema presenta la historia de un hombre molido a palos por el amante de un Pierrot disfrazado que había hallado en la calle.

Sucede algo similar cuando Xammar interpreta el poema "Bromas de la aldea", donde unos muchachos escuchan el deseo de un viajero de encontrar consuelo en una mujer, y el texto concluye:

Así dijo el viajero...

Nos miramos,

sonó una risotada contenida, sonaron veinte luego, y en seguida

como no lo entendimos, lo apedreamos. (Yerovi, 2006, p. 522)

Xammar lee estos versos:

"Como no lo entendimos lo apedreamos". Aquí. Yerovi excede su conformidad y pronuncia una voz de aguda desesperación. Es como una revancha que su verdadera personalidad se cobra contra "el otro Yerovi” que forjaba su público: el Yerovi perennemente alegre y sonriente, "chistoso". Qué duro debió haber sonado este adjetivo para el poeta, que se conocía más allá del "chiste", de la broma episódica de su ingenio vivaz. Y si en vida quien le dio popularidad y fama fue el Yerovi alegre, a su muerte "el otro Yerovi” tuvo emocionada justificación. (1938, p. 58) 
Esta interpretación utiliza algunas líneas del poema como una ventana a la psicología del poeta. Se nos muestran dos "Yerovis", uno es real y el otro, una máscara. La máscara sería su imagen pública como humorista, la manera en que decide presentarse ante su público masivo, mientras que aquel Yerovi "real" portaría una amargura profunda, una sensibilidad melancólica ante el mundo, y sería la fuente de su creación artística. Esta visión también significa que la crítica debe saber separar lo superfluo, lo anecdótico, de aquellas profundas heridas que nos lleven a conocer la interioridad del poeta. Algo similar sucede en algunos capítulos de La casa de tantos:

El 9 de setiembre, hace apenas dos días, cumplí quince años, soy mucho más sereno, más sensible y más grave de lo que permito que la gente crea, ya que sólo dejo ver mi ánimo habitualmente bien humorado y bien dispuesto para la chanza. (Yerovi, 2001, p. 100)

En este capítulo, se utiliza la primera persona para ingresar a la subjetividad del joven poeta como contraposición a su aspecto externo similar a lo que pudo observarse en la escena de su muerte: siempre la risa y la broma como actitud contestataria. Esta duplicidad es necesaria para crear una imagen de Yerovi como héroe romántico, solo en su conciencia y mostrando una máscara ante el mundo.

Para el héroe, lo que da alas a la voluntad y le hace volar más allá del desfiladero de la desesperación es, precisamente, esta percepción absoluta de la propia condición. Este hecho le precipita a la soledad más extrema, pero en ella reconoce la frágil frontera que sitúa al placer al costado del dolor. (Argullol, 1999, p. 271)

\section{Conclusiones}

$\mathrm{E}$ n el presente artículo, hemos rastreado una de las líneas de investigación que ha seguido la crítica sobre Leonidas Yerovi, según la cual su vida presenta cualidades literarias y merece ser novelada. En primer lugar, revisamos los textos más importantes acerca de su trágica muerte para mostrar no solo la centralidad que este hecho tuvo en varios escritos sobre el autor, sino también cómo es que se le atribuyen características literarias y se asume 
una concordancia con su actitud ante la vida. Desde el primer momento, se crea literatura basada en la muerte de Yerovi, como demuestra el discurso de Abraham Valdelomar, y se tiene consciencia de que, de alguna forma, ilumina su constitución como personaje.

En segundo lugar, exploramos cómo varios críticos han utilizado algunos versos para relacionarlos con su biografía, incluso de maneras injustificadas. Se demuestra así que, al momento de construir una imagen de héroe romántico para Yerovi, se le ha hecho otra de poeta romántico, guiado por sus impulsos emocionales (y todo esto en desmedro al interés por el estudio de su obra). Finalmente, la amargura de Leonidas Yerovi se desarrolla como la contracara a su escritura risueña. La risa parece resultar superficial y burda si no presenta un trasfondo de sufrimiento y de spleen. Nuestro poeta es convertido así en un personaje romántico, solo en su mundo interior, y el deber de la crítica sería descubrir a este Yerovi "real" detrás de la máscara que sonríe. Mientras tanto, la obra de Leonidas Yerovi, y especialmente su poesía, permanece a la espera de críticos que la valoricen por sí misma y no a la sombra de la deslumbrante vida bohemia de su autor.

\section{Referencias}

Argullol, R. (1999). El héroe y el único. El espiritu trágico del Romanticismo. Madrid, España: Aguilar, Altea, Taurus, Alfaguara.

Chávez Costa, A. (1991). Periodismo y humor... Lima, Perú: IDE Editores.

Chiarella Viale, M. (2012). La suerte en la obra teatral de Leonidas N. Yerovi. (Tesis de licenciatura, Pontificia Universidad Católica del Perú, Lima, Perú).

Genette, G. (1989). Palimpsestos. La literatura en segundo grado. Madrid, Espańa: Altea, Taurus, Alfaguara.

More, F. (1989). Andanzas de Federico More. Lima, Perú: Editorial Navarrete.

Pinto Gamboa, W. (1973). La sátira en Valdelomar y en Yerovi. (Tesis de doctorado, Universidad Nacional Mayor de San Marcos, Lima, Perú).

Rivera Saavedra, J. (2007). Historia del teatro peruano. Lima, Perú: Universidad Alas Peruanas. 
Salcedo, J. M. (2006). Ironía y prosa periodística. En Yerovi, L., Obra Completa. Tomo II (pp. XIX-XXIV). Lima, Perú: Fondo Editorial del Congreso del Perú.

Sánchez, L. A. (1933). América: novela sin novelistas. Lima, Perú: Editorial Librería Peruana.

Sánchez, L. A. (1966). Literatura peruana: derrotero para una historia cultural del Perú. Tomo IV. Lima, Perú: Ediciones Ediventas.

Silva-Santisteban, R. (1993). La música de la humanidad. Antología poética del Romanticismo inglés. Barcelona, España: Tusquets Editorial.

Tamayo Vargas, A. (1969). Prólogo. En Yerovi, L. Poesía y teatro. Lima, Perú: Editorial Horizonte.

Valdelomar, A. (2006). Discurso en el entierro de Leonidas Yerovi. En Yerovi, L., Obra completa. Tomo III. Lima, Perú: Fondo Editorial del Congreso del Perú.

Xammar, L. F. (1938). Valores humanos en la obra de Leonidas Yerovi. Lima, Perú: Editorial Antena.

Yerovi, L. (2006). Obra completa. Tomo III. Lima, Perú: Fondo Editorial del Congreso del Perú.

Yerovi, N. (2001). La casa de tantos. Lima, Perú: Editorial PEISA. 